\title{
CAVITATION SIMULATION OF CENTRIFUGAL PUMP WITH DIFFERENT INLET ATTACK ANGLES
}

\author{
Hu, Q. X. ; Yang, Y.* \& Shi, W. D.,**,\# \\ * Research Institute of Fluid Engineering Equipment Technology, Jiangsu University, Zhenjiang \\ 212013, China \\ ${ }^{* *}$ School of Mechanical Engineering, Nantong University, Nantong 226019, China \\ E-Mail:wdshi@ujs.edu.cn ( ${ }^{\#}$ Corresponding author)
}

\begin{abstract}
The impeller passage of low-specific-speed centrifugal pump is long and narrow. As cavitation occurs, the cavity blocks the passage abruptly, resulting in performance deterioration. Numerical simulation and a hydraulic test were conducted on a low-specific-speed centrifugal pump at three different inlet attack angles $\left(8^{\circ}, 0^{\circ}\right.$, and $\left.-8^{\circ}\right)$ to clarify the influence of inlet attack angle on cavitation evolution in the impeller. The cavity distribution in the cavitation flow field and the blade loading distribution were analysed. Results showed that as the cavitation number decreased, the cavity initially emerged on the suction surface of the blade leading edge then extended rapidly to the impeller outlet along the blade surface. Meanwhile, the cavity spread to the pressure surface from the suction side under the influence of the re-entrant jet. Pump performance sharply deteriorated as the cavity grew to about $1 / 3$ of the blade length. The loading on the blade close to the tongue was higher than that on the other blades regardless of whether cavitation occurred or not, and the zero-loading zone at the complete cavitation stage occupied about $3 / 5$ of the length of flow passage.

(Received in March 2020, accepted in May 2020. This paper was with the authors 3 weeks for 1 revision.)
\end{abstract}

Key Words: Centrifugal Pump, Cavitation, Numerical Calculation, Blade Loading, Inlet Attack Angle

\section{INTRODUCTION}

Cavitation occurs when liquid pressure is lower than vaporization pressure. In fluid machinery with high rotation speed, such as propellers and pumps, cavitation occurs because of the flow acceleration and pressure reduction on the blade surface [1]. The cavity occupies the entire runner rapidly after cavitation inception due to the narrow passage between the blades of low-specific-speed centrifugal pumps; thus, the pump head efficiency decreases sharply [2]. Cavitation has consistently been a primary issue in studies on pump capability. Cavitation in pumps cannot be completely eliminated on the basis of the saturated vapour pressure hypothesis [3]. The energy exchange between the solid wall and the liquid is affected by the evolution of cavitation in the passage, resulting in the deterioration of hydraulic performance (head and efficiency reduction). Cavitation collapse causes blade surface failure, and the associated vibration and noise affect the safety and stability of pump operation $[4,5]$. The design theory involving low specific speed at present is still based on the affinity law and velocity coefficient method [6-9] and depends largely on the experience of designers. The cavitation distribution in the low-specific-speed centrifugal pumps and its internal evolution should be investigated to optimize the anti-cavitation capability of these pumps.

On this basis, researchers have explored the influence of the design parameters of lowspecific-speed centrifugal pump on anti-cavitation performance [10-13]. However, only a few in-depth studies on the cavitation evolution characteristics of this type of pump have been conducted based on positive or negative inlet attack angle of the blade. The positive inlet attack angle is frequently utilized for low-specific-speed centrifugal pump to reduce the inflow impact. Cavitation flow field analyses of the negative or zero attack angles have rarely been performed. Therefore, the influence of inlet attack angle on the cavitation of low- 
specific-speed centrifugal pump and the change in flow field must be investigated. In the current study, a centrifugal pump with a specific speed of 44 was designed to study the influence of the inlet attack angle of the blade on the cavitation of the low-specific-speed centrifugal pump and ascertain the characteristics, such as cavity distribution and blade loading at successive cavitation stages of the pump. The results were then compared to provide a reference for the optimum design of the anti-cavitation performance of centrifugal pump.

\section{STATE OF THE ART}

With the development of computational fluid dynamics (CFD), many scholars worldwide have conducted substantial research on the cavitation characteristics of low-specific-speed centrifugal pump via theoretical calculation, numerical simulation, and experimentation. As for theoretical calculation, Iga et al. [14] deduced the rate equations of cavitation on the cascade surface on the basis of mass and momentum conservation equations. Then, they conducted a comparative visualization experiment and found that the theoretically predicted cavitation structure was similar to that observed in the cascade flow field. Kunz et al. [15] predicted the occurrence and evolution of single airfoil cavitation by using a two-phase flow model based on the Navier-Stokes equation. On this basis, the present study conducted a numerical simulation analysis and research on a low-specific-speed centrifugal pump and investigated the anti-cavitation performance. Ye et al. [16] proposed a semi-analytical cavitation model based on the Zwart cavitation model and obtained improved prediction results of large-scale cavity; however, the shedding frequency of the cavitation cloud was lower than that in the test data. With regard to numerical calculation, Luo et al. [17-18] conducted simulation with the volume-of-fluid cavitation model to investigate a boiler feedwater pump and analysed the influence of impeller inlet geometric parameters on cavitation. However, the boiler feedwater pump is beyond the range of the low-specific-speed pump and generally used to convey high-temperature fluid. It has different temporal and spatial evolution features in comparison with low-specific-speed centrifugal pump. Gao et al. [19] studied the influence of cavitation in moderate-specific-speed centrifugal pump and revealed that incipient cavitation is located near the suction surface of impeller inlet. As cavitation becomes serious, the pressure pulsation frequency in the flow passage exhibits an obvious discrete characteristic; with the deterioration of cavitation, the amplitude of the pressure pulsation increases. Medvitz et al. [20] studied the relationship between flow coefficient and cavitation number by using a homogeneous model to deal with the momentum and volume continuity equations of liquid and vapour phases. They found that the steep drop of the external characteristic is due to the blockage of the flow passage by cavity. The mechanism of the steep drop in performance was investigated, but the entire cavitation evolution was not examined. Tang et al. [21] conducted numerical research on a doublesuction centrifugal pump to analyse the influence of cavitation number on blade loading. The blade loading increased slightly in the initial stage of cavitation, but the blade loading near the impeller inlet decreased to zero and even became negative. Only blade loading was considered in this study, and the changes caused by cavitation in the flow field were not associated. Bakir et al. [22] optimized anti-cavitation performance by adding an inducer in front of the inlet of the centrifugal pump. Cavitation appeared later than that in the case without an inducer due to the increase in pressure at the inlet. Azad et al. [23] conducted a visualization experiment to investigate the cavitation of a centrifugal pump with transparent pump casing and polyacrylamide solution flow medium. The quantity of bubbles was ascertained to determine the cavitation level. The researchers found that the generation of bubbles is delayed when the fluid concentration increases. Lu et al. [24] studied the pressure 
pulsation at various positions in centrifugal pump by collecting pressure signals through sensors. The results revealed that the dominant frequency at the inlet and outlet is still shaft frequency and blade passing frequency. However, due to the random shedding and transient rupture of the cavity, broadband pulsation occurred at the inlet and outlet. As the cavitation deteriorated, broadband pulsation became increasingly obvious, and the pulsation amplitude increased. Guo et al. [25] used high-speed photography to capture the cavitation flow field of a high-specific-speed centrifugal pump assembled with a transparent pump casing and impeller. The generation, development, and collapse of the cavity were observed, and cavitation evolution was found to be consistent with the change in the flow-head curve.

These research results indicate that the existing description of cavitation evolution in centrifugal pumps is still based on the airfoil or cascade model, and each stage of cavitation is not clearly divided. With regard to the structural parameters that affect cavitation, few studies have been conducted on the influence of positive and negative inlet attack angles. On the basis of numerical simulation and hydraulic testing, this study explored the flow structure of cavitation evolution in a low-specific-speed centrifugal pump with different inlet attack angles to provide guidance for the optimization design of low-specific-speed centrifugal pumps.

The remainder of this paper is arranged as follows. Section 3 shows the design parameters, numerical calculation method, and the design of test bed. Section 4 discusses the influence of inlet attack angle on cavitation in the low-specific-speed centrifugal pump through a comparative analysis of cavitation evolution stages and blade loading. Section 5 summarizes the study and provides the conclusions.

\section{METHODOLOGY}

\subsection{Geometric model}

A typical low-specific-speed centrifugal pump was adopted as the study object, and three impellers with different inlet attack angles $\Delta \beta\left(-8^{\circ}, 0^{\circ}\right.$, and $\left.8^{\circ}\right)$ were designed. The blade outlet angle was $\beta_{2}=27.5^{\circ}$, the blade wrap angle was $\varphi=165^{\circ}$, and the blade thickness was 3-5-8 $\mathrm{mm}$. The other design parameters are shown in Table I. Fig. 1 presents the axial projection drawings and front views of the impellers.

Table I: Design parameters of the model pump.

\begin{tabular}{|l|c|}
\hline \multicolumn{1}{|c|}{ Parameter } & Value \\
\hline Specific speed $n_{\mathrm{s}}$ & 44 \\
\hline Flow rate $Q\left(\mathrm{~m}^{3} \cdot \mathrm{h}^{-1}\right)$ & 10 \\
\hline Head $H(\mathrm{~m})$ & 11 \\
\hline Rotating speed $n(\mathrm{rpm})$ & 1450 \\
\hline Impeller diameter $D_{2}(\mathrm{~mm})$ & 192 \\
\hline Inlet diameter $D_{1}(\mathrm{~mm})$ & 54 \\
\hline Impeller outlet width $b_{2}(\mathrm{~mm})$ & 5 \\
\hline Hub diameter $d_{\mathrm{h}}(\mathrm{mm})$ & 20 \\
\hline
\end{tabular}

\subsection{Numerical simulation}

ANSYS ICEM was used to generate high-quality hexahedral meshes in the computational domains of the model pump. Fifteen mesh layers were added to each boundary while guaranteeing that the distribution of blocks was accordance with the flow regime in the computational domains to ensure the accuracy of the numerical simulation in the near-wall zone. 


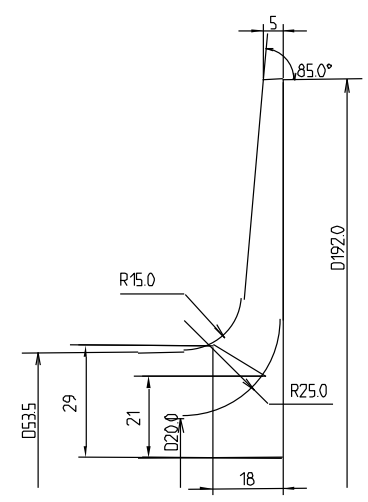

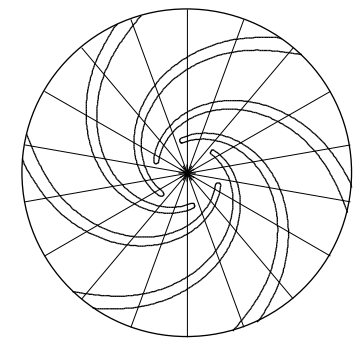

a)

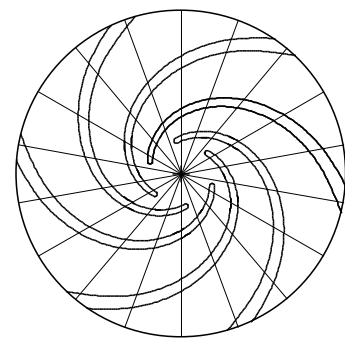

b)

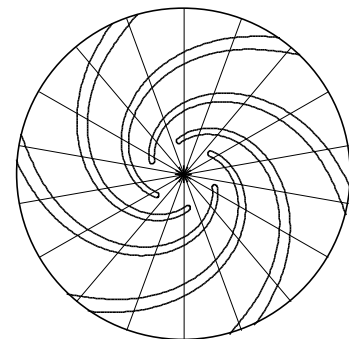

c)

Figure 1: Views of impellers; a) $\Delta \beta=-8^{\circ}$, b) $\Delta \beta=0^{\circ}$, c) $\Delta \beta=8^{\circ}$.

Mesh independence was applied under the design condition to guarantee calculation accuracy and improve calculation efficiency. When the grid number exceeded 2.6 million, the change in the pump head was within $1 \%$. Thus, the grid number was determined. Fig. 2 shows a 3D model of the computational domain, and Fig. 3 shows a schematic of the computation meshes. The left side presents the cross-section mesh of the impeller and volute, and the right side shows partial enlargement of the mesh at the inlet and outlet of blade.

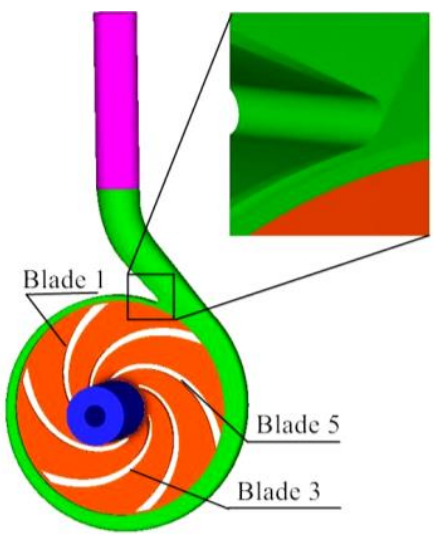

Figure 2: Computational domain.

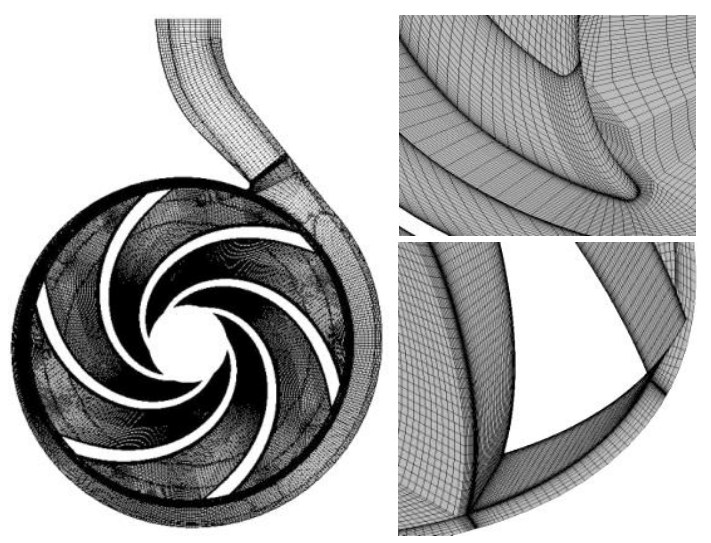

Figure 3: Schematic of the mesh.

Steady-stage computation of multiple working conditions was performed with different inlet attack angles by using ANSYS-CFX 17.0 software. Given that NPSH (Net Positive Suction Head) is closely related to the pressure at the pump inlet, the total pressure in the inlet and the mass flow in the outlet were used for the computational domain. The impeller was set as the rotational domain, and the other parts were considered static. The volume fraction of the cavity at the inlet was $10 \mathrm{E}-15$. The wall roughness was $0.02 \mathrm{~mm}$. The near-wall parameters were computed using the standard wall function. The calculations for noncavitation simulation were used as the initial results for the cavitation simulation to reduce the calculation time.

Time-averaged N-S equations were utilized as the basic governing equations in the singlephase computation. The SST $k$ - $\omega$ turbulence model was selected for 3D turbulence numerical simulation because it considers the transmission of turbulence shear stress and can accurately predict the initial position and results of fluid separation under turbulent negative-pressure gradient. The transport behaviour was obtained using the eddy viscosity equation containing the limiting quantity

$$
v_{t}=\frac{\alpha_{1} k}{\max \left(a_{1} \omega, S F_{2}\right)}
$$

where $v_{\mathrm{t}}$ denotes dynamic viscosity, $a_{1}$ is a constant taken as $5 / 9, k$ is turbulent kinetic energy, 
$\omega$ is turbulence frequency, $F_{2}$ is mixing function that constrains the limiting quantity in the boundary layer, and $S$ is the invariant measure of shear rate.

A homogeneous model was used in the vapour-liquid two-phase flow field. The Zwart equation based on the Rayleigh-Plesset formula was used to analyse the generation and collapse of cavitation bubbles and the mass transfer in the fluid. The evolution process of cavitation bubbles is given as

$$
R_{B} \frac{d^{2} R_{B}}{d t^{2}}+\frac{3}{2}\left(\frac{d R_{B}}{d t}\right)^{2}+\frac{2 \sigma}{\rho_{f} R_{B}}=\frac{p_{v}-p}{\rho_{f}}
$$

where $R_{\mathrm{B}}$ is the radius of bubble, $p_{\mathrm{v}}$ is the pressure inside a bubble, $p$ is the pressure of the fluid around bubble, $\rho_{f}$ is the density of the fluid, and $\sigma$ is the surface tension of the interface between the fluid and bubble.

\subsection{Establishment of the test bed}

Figs. $4 \mathrm{a}$ and $4 \mathrm{~b}$ present an image of the test field and the general design of the testing apparatus, respectively. The experiment equipment and field were provided by Jiangsu University. The closed-type test bed was composed of pump and data acquisition systems. The flow loss of the inlet pipeline was changed by regulating the inlet valve to reduce the inlet pressure for simulating the cavitation condition. During the experiment, the inlet valve was regulated to the maximum, and the motor was initialized to $1450 \mathrm{r} / \mathrm{min}$. The flow rate and inlet and outlet pressures were recorded. This working condition was regarded as the noncavitation condition. Then, the inlet valve opening was gradually reduced to realize inlet pressure reduction. In consideration of the safety of the test bed, the experiment was stopped when a steep head drop occurred. The experiment for each condition was repeated 3-5 times to reduce the test error.

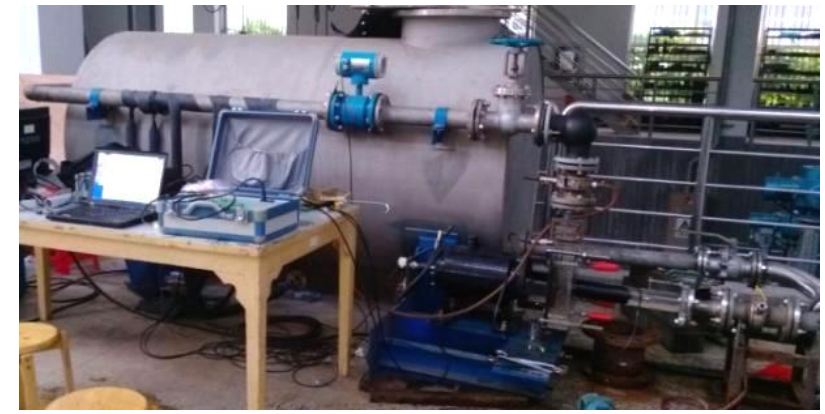

a)

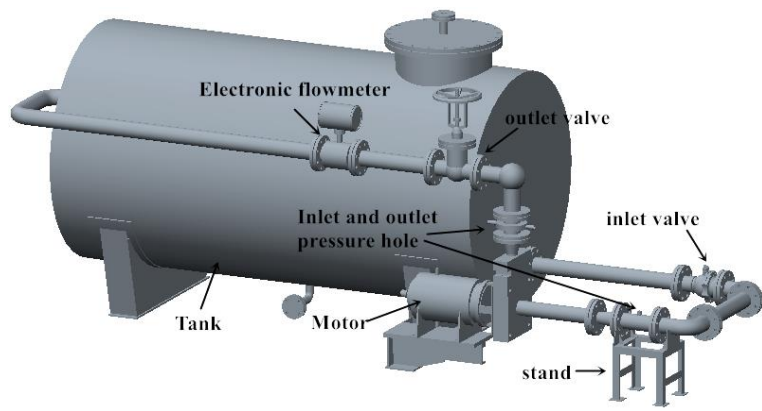

b)

Figure 4: Test bed; a) Test field, b) Testing apparatus.

Fig. 5 shows a comparison of experimental and numerical external characteristics under the noncavitation condition. A similar change trend was observed. The error of the computed pump head was about $2 \%-5 \%$ at each testing flow rate. As shown in the figure, the head varied slightly when the inlet attack angle changed from $-8^{\circ}$ to $8^{\circ}$.

Fig. 6 shows a comparison of cavitation performance in the numerical simulation and testing. Cavitation occurred in the pump when the inlet pressure was decreased. The numerical and experiment results showed the same trend, but the results computed by CFD were slightly higher than the test results; the error was about $2 \%$. With the same inlet attack angle, the anti-cavitation capability worsened as flow rate increased. The anti-cavitation performance of the impeller with inlet attack angles of $8^{\circ}$ and $0^{\circ}$ was close and better than that of the impeller with inlet attack angle of $-8^{\circ}$. 


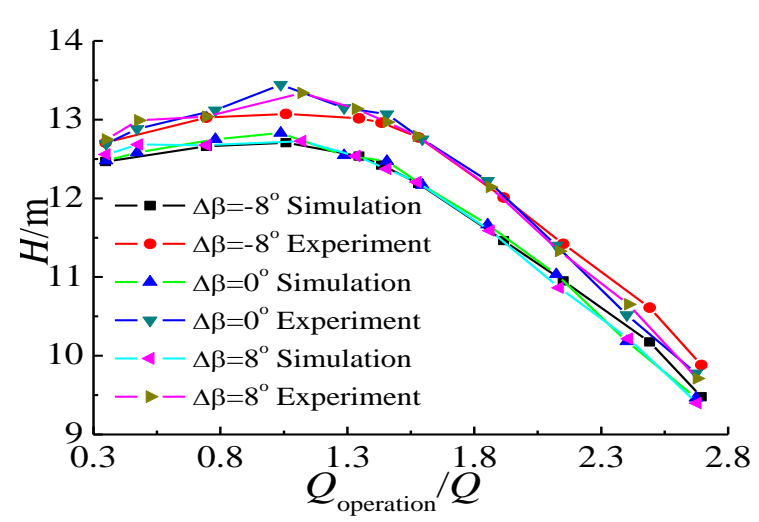

Figure 5: Head in the noncavitation condition.

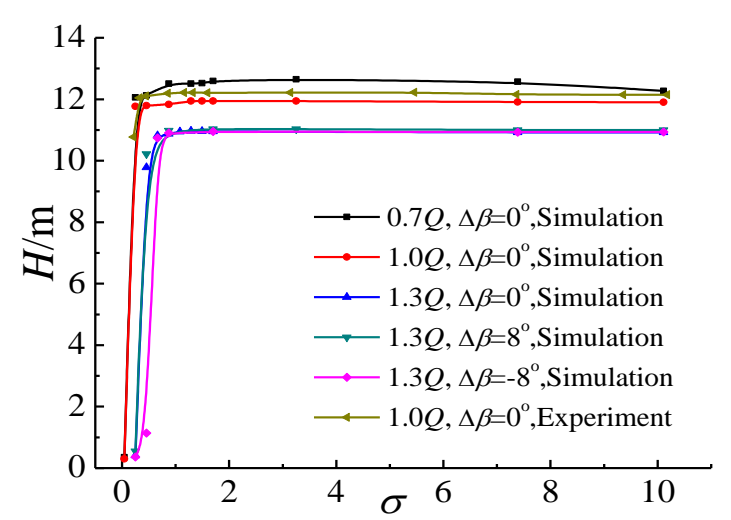

Figure 6: Cavitation performance in the numerical simulation and testing.

\section{RESULT ANALYSIS AND DISCUSSION}

\subsection{Definition of dimensionless parameters}

Cavitation number $\sigma$ is defined as

$$
\sigma=\frac{p_{1}-p_{v}}{\frac{1}{2} \rho U^{2}}
$$

where $p_{1}$ is the total pressure at the impeller inlet, $p_{\mathrm{v}}$ is the saturated vapour pressure taken as $3574 \mathrm{~Pa}$, and $U$ is the reference velocity set as the circumferential velocity at the intersection point of the leading edge of the blade and the front cover plate.

Pressure coefficient $C_{\mathrm{p}}$ is defined as

$$
C_{p}=\frac{p-p_{1}}{\frac{1}{2} \rho U^{2}}
$$

and pressure difference coefficient $\Delta p$ is defined as

$$
\Delta_{p}=\frac{p_{\mathrm{ps}}-p_{\mathrm{ss}}}{\frac{1}{2} \rho U^{2}}
$$

where $p_{\mathrm{ps}}$ and $p_{\mathrm{ss}}$ are the static pressure on the pressure and suction sides at the same radius.

Radial coefficient $r^{*}$ is defined as

$$
r^{*}=\frac{2 r}{D_{2}}
$$

where $r$ is the radical distance of the force-bearing point and $D_{2}$ is the diameter of the impeller.

\subsection{Cavitation evolution}

The cavitation volume fraction was taken as 0.1 when defining the boundary of the cavity in CFX-POST to analyse the stages of cavitation evolution in the impeller. As shown in Fig. 7, at the same flow rate, the cavitation zone gradually extended along the surface of the blade with the decrease in cavitation number until the stage of developed cavitation arrived. The cavity rapidly spread from the impeller inlet to block the entire passages. At the beginning of cavitation, the pump head exhibited little variation. The cavitation became serious to some degree when an obvious decline occurred. The cavitation initially appeared on the suction side of the blade leading edge, and the distribution of cavitation in each passage was asymmetric. 
With the same cavitation number $\sigma$, the cavitation under $1.3 Q$ flow rate was the most serious, whereas that under $0.7 Q$ flow rate was the least serious. The impeller with $\Delta \beta=8^{\circ}$ exhibited the best anti-cavitation performance, whereas that with $\Delta \beta=-8^{\circ}$ exhibited the worst. When the length of the cavity reached about $1 / 3$ of the blade length, the spread of the cavitation zone encountered obvious inhibition, and the cavity extended to the middle part of the passages under the influence of re-entrant jet.

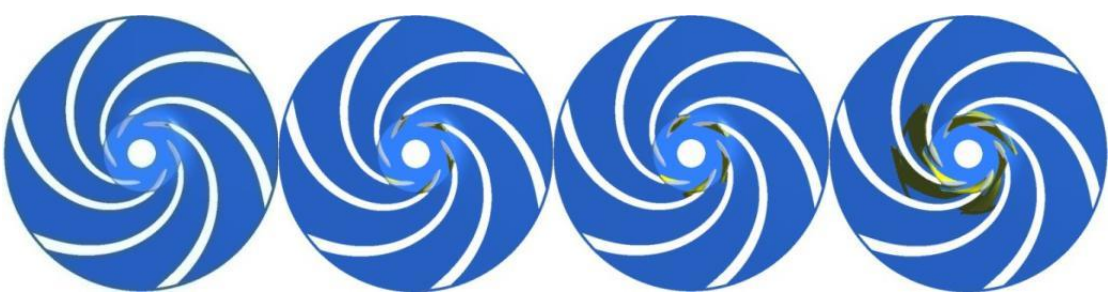

$0.7 Q \Delta \beta=0^{\circ}$

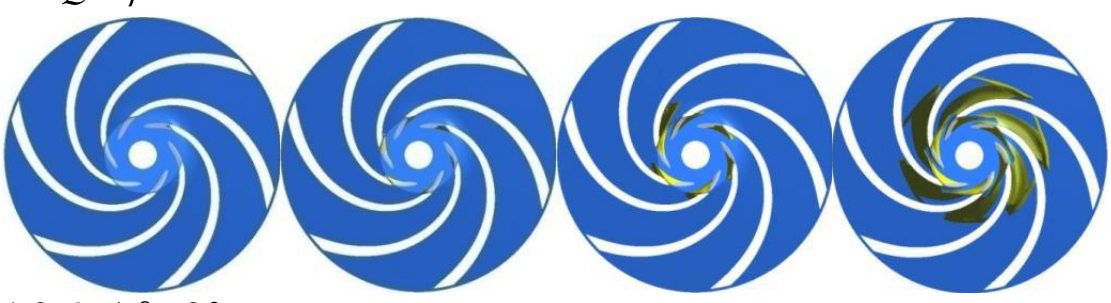

$1.0 Q \Delta \beta=0^{\circ}$

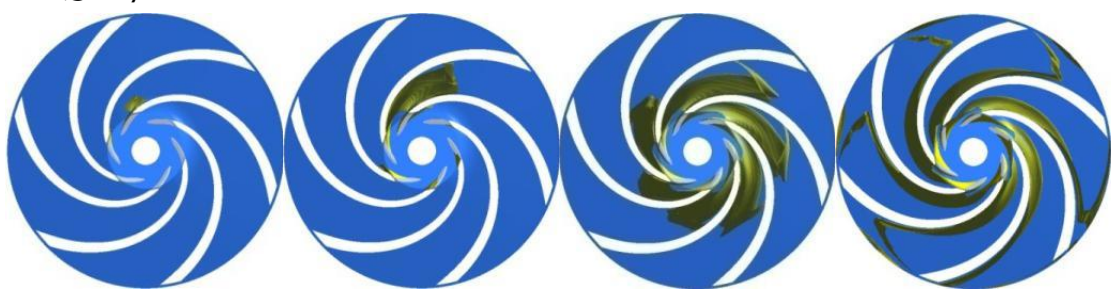

$1.3 Q \Delta \beta=0^{\circ}$
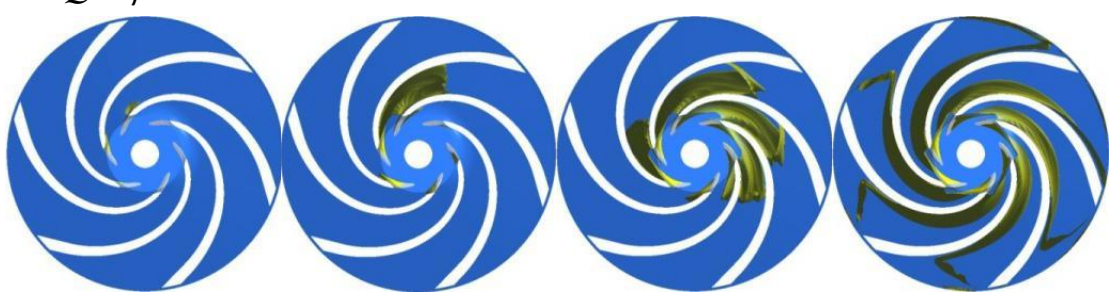

$1.3 Q \Delta \beta=8^{\circ}$

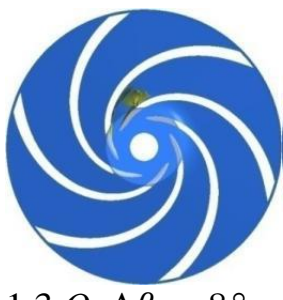

$1.3 Q \Delta \beta=-8^{\circ}$

a)

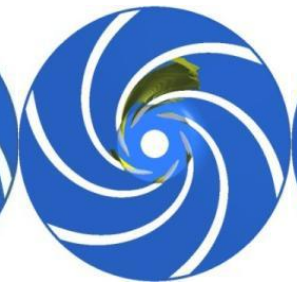

b)

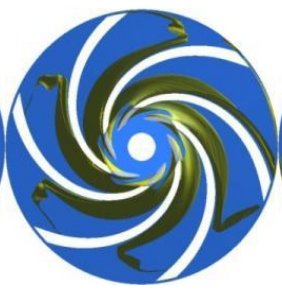

c)

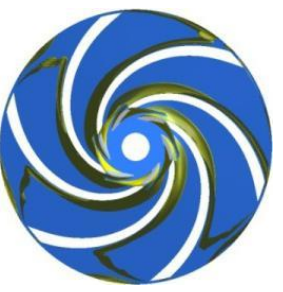

d)

Figure 7: Cavitation evolution in the impeller; a) $\sigma=1.6993$, b) $\sigma=0.8717$, c) $\sigma=0.4579$, d) $\sigma=0.2510$.

The blade-to-blade flow fields in cascades were extracted in CFD Turbo, as shown in Fig. 8 , to distinguish the successive stages of cavitation evolution in the impeller. The cavitation number $\sigma$ is $1.6993,0.8717,0.4579$, and 0.2510 from left to right in the figure, and the arrow points to the position of the tongue. The process was divided into four stages. During the stage of incipient cavitation, attached cavities appeared on the suction side of the blade leading edge, and the external characteristics presented minimal changes. During critical 
cavitation, the cavity spread to the impeller outlet along the blade suction surface with the decrease in $\sigma$. When the cavity length reached about $1 / 3$ of the blade length, the head decreased by $3 \%$. During developed cavitation, the cavity was clearly separated from the surface and spread to the middle part of the passage as $\sigma$ continued to decrease. The cavitation trail formed at the front zone of the cavity due to the re-entrant jet, and the length of the cavity was about $1 / 2-2 / 3$ of the blade length. During the stage of complete cavitation, the cavity spread to the impeller outlet and blocked the passage. Thus, the impeller lost the capability to convey fluid. When $\sigma$ is 1.6993 and 0.8717 , the cavitation distribution was similar, and the incipient positions of cavitation under different $\Delta \beta$ remained almost the same. Moreover, cavitation initially emerged on the suction side of the leading edge of the blade close to the tongue. The volume growth rate of cavitation was low from incipient cavitation to developed cavitation stages. After reaching the stage of developed cavitation, the cavitation zone increased abruptly until the cavity blocked the impeller outlet. The cavity rapidly filled up the entire passages at the stage of developed cavitation due to the long, narrow passage of the low-specific-speed centrifugal pump. A steep drop occurred on the head curve. The large expelling coefficient at $\Delta \beta=-8^{\circ}$ affected the flow uniformity at the inlet, resulting in poor anti-cavitation performance.

Table II shows the critical cavitation number $\sigma_{a}$ under various conditions. $\sigma_{a}$ is defined as the cavitation number when the head decreases by $3 \% . \sigma_{a}$ increased with the increase in flow rate, and the influence of enlarging the flow rate was greater than the effect of reducing the flow rate. At the same flow rate, the impeller with $\Delta \beta=-8^{\circ}$ reached critical cavitation, followed by the impellers with $\Delta \beta=0^{\circ}$ and $\Delta \beta=8^{\circ}$.

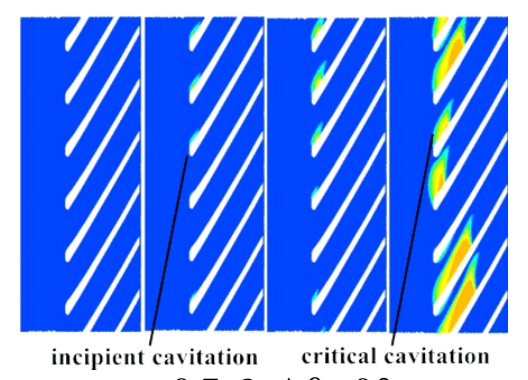

$0.7 Q \Delta \beta=0^{\circ}$

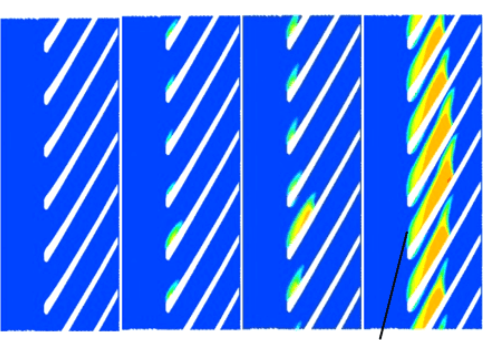

developed cavitation $1.0 Q \Delta \beta=0^{\circ}$

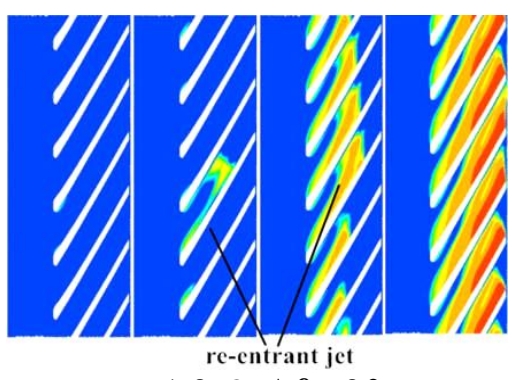

$1.3 Q \Delta \beta=0^{\circ}$

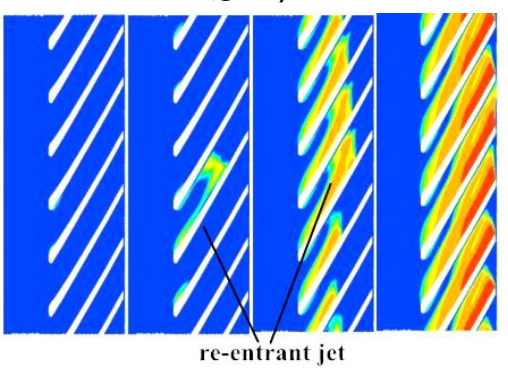

$1.3 Q \Delta \beta=8^{\circ}$

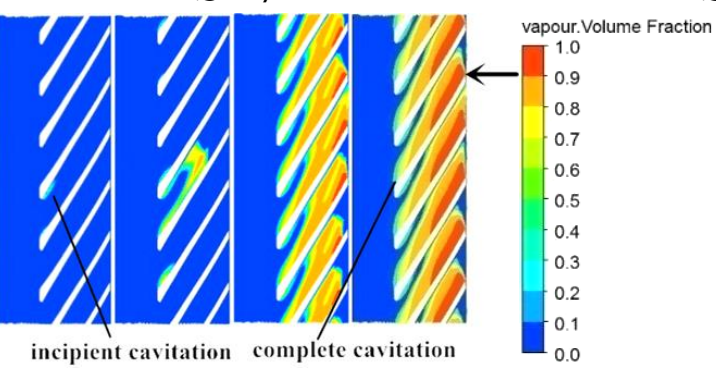

$1.3 Q \Delta \beta=-8^{\circ}$

Figure 8: Cavitation evolution in cascades.

Table II: Critical cavitation number under various conditions.

\begin{tabular}{|c|c|c|c|c|c|}
\hline Inlet attack angle & \multicolumn{3}{|c|}{$\Delta \beta=0^{\circ}$} & $\Delta \beta=8^{\circ}$ & $\Delta \beta=-8^{\circ}$ \\
\hline Flow rate & $0.7 Q$ & $1.0 Q$ & $1.3 Q$ & $1.3 Q$ & $1.3 Q$ \\
\hline Critical cavitation number $\sigma_{a}$ & 0.2510 & 0.3521 & 0.6619 & 0.6271 & 0.6871 \\
\hline
\end{tabular}

The blade loading varied as the cavitation evolved. Fig. 10 shows the distribution of pressure coefficient $C_{\mathrm{p}}$ on Blades $1-6$. The $C_{\mathrm{p}}$ on the pressure surface was a convex function of radial coefficient $r^{*}$, and the $C_{\mathrm{p}}$ on the suction surface was a concave function of $r^{*}$. Under 
low flow rate $(0.7 Q)$, the $C_{\mathrm{p}}$ on the blades exhibited obvious asymmetry, especially at the trailing edge of Blades 5 and 6 . This result reveals that the interference effect was enhanced at low flow rate. The variation in the pressure coefficient was not observable before critical cavitation occurred. For the impeller with $\Delta \beta=0^{\circ}$, when the stage of critical cavitation was reached under $0.7 Q$ flow rate, the length of the low-pressure zone was about $1 / 3$ of the blade length. At the stage of developed cavitation, the low-loading zone spread toward the impeller outlet, and the asymmetry of $C_{\mathrm{p}}$ on the blades increased. After reaching the stage of complete cavitation, the $C_{\mathrm{p}}$ on the suction pressure became negative, and the low-loading zone reached about $3 / 5$ of the blade length.
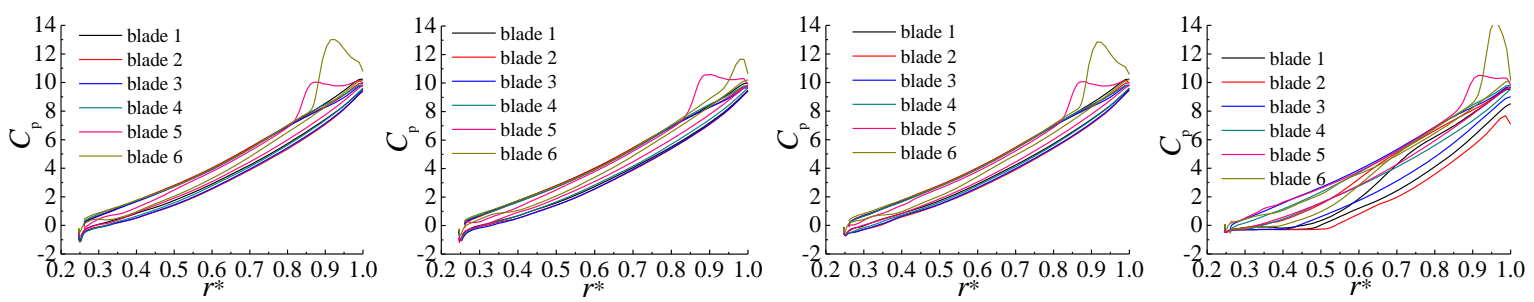

$0.7 Q \Delta \beta=0^{\circ}$
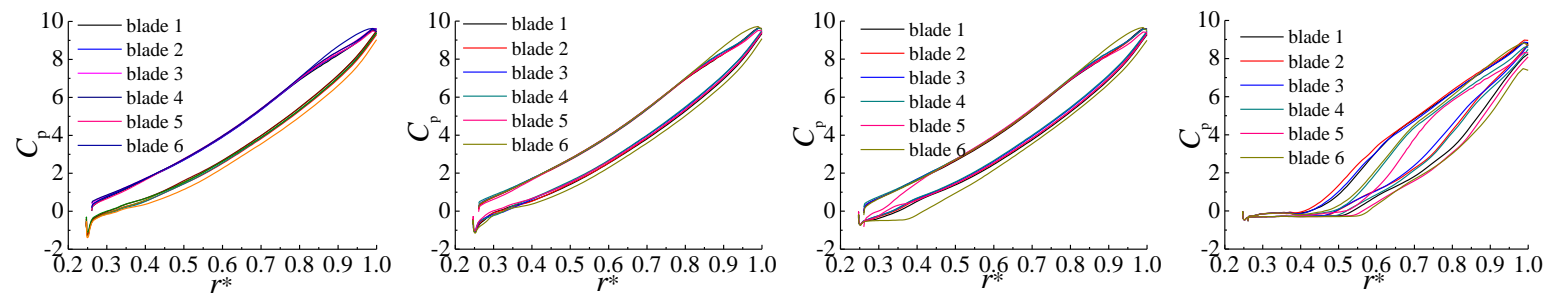

$1.0 Q \Delta \beta=0^{\circ}$
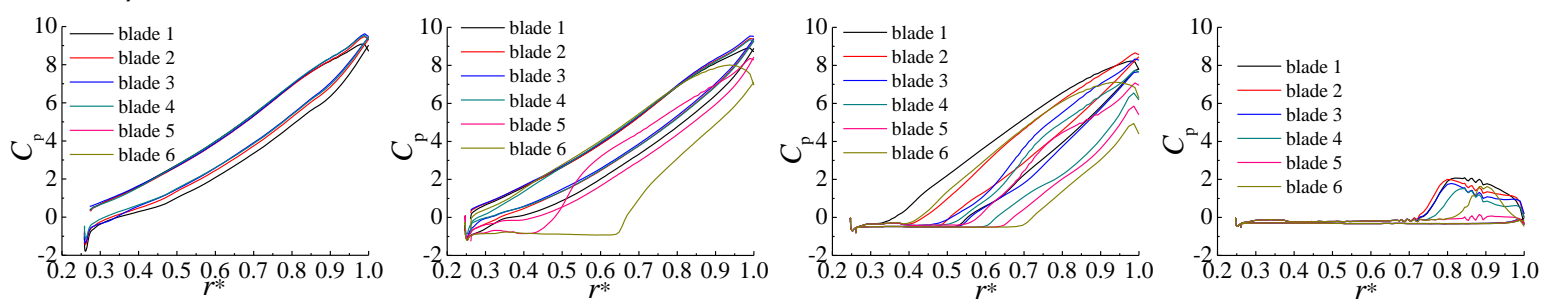

$1.3 Q \Delta \beta=0^{\circ}$
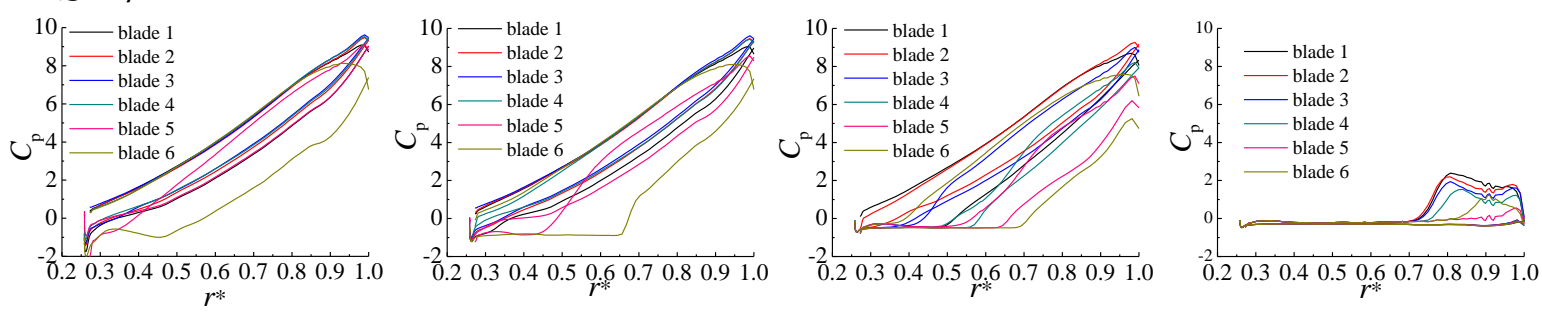

$1.3 Q \Delta \beta=8^{\circ}$

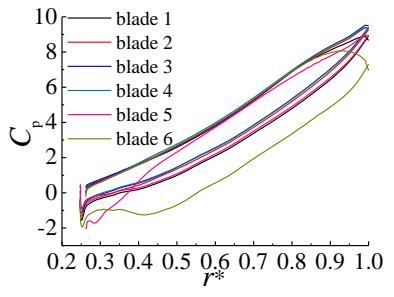

$1.3 Q \Delta \beta=-8^{\circ}$

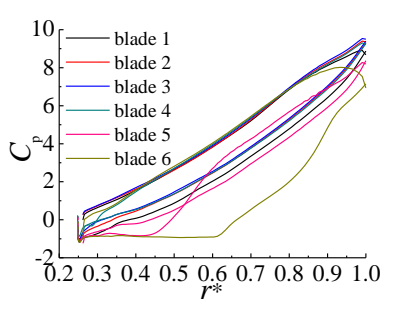

b)

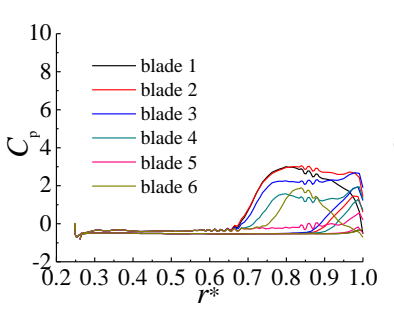

c)

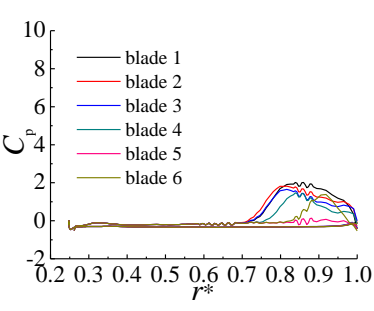

d)

Figure 10: Distribution of the pressure coefficient on blades;

a) $\sigma=1.6993$, b) $\sigma=0.8717$, c) $\sigma=0.4579$, d) $\sigma=0.2510$. 
Fig.11 shows the pressure difference coefficient, $\Delta p$, of the blades on the cross section of the impeller. $\Delta p$ increased linearly at first, but due to the wake and secondary flow, it decreased rapidly at the trailing edge. At the flow rate of $0.7 Q$, the distribution of $\Delta p$ presented the most obvious difference. Before critical cavitation occurred, the variation tendency of $\Delta p$ of Blades 1-4 was similar. $\Delta p$ remained at about 0.5 then increased abruptly to 4.5 at $r^{*}=0.8$; then, it decreased to 0 at the trailing edge. At flow rates of $1.0 Q$ and $1.3 Q$, the $\Delta p$ of Blade 6 was larger than that of Blade 1-5, and cavitation also emerged initially on the suction surface of Blade 6 .
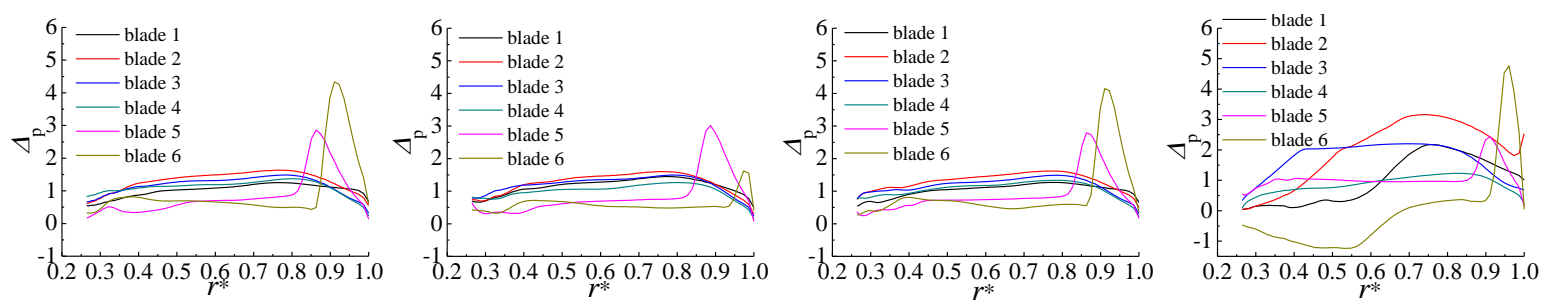

$0.7 Q \Delta \beta=0^{\circ}$
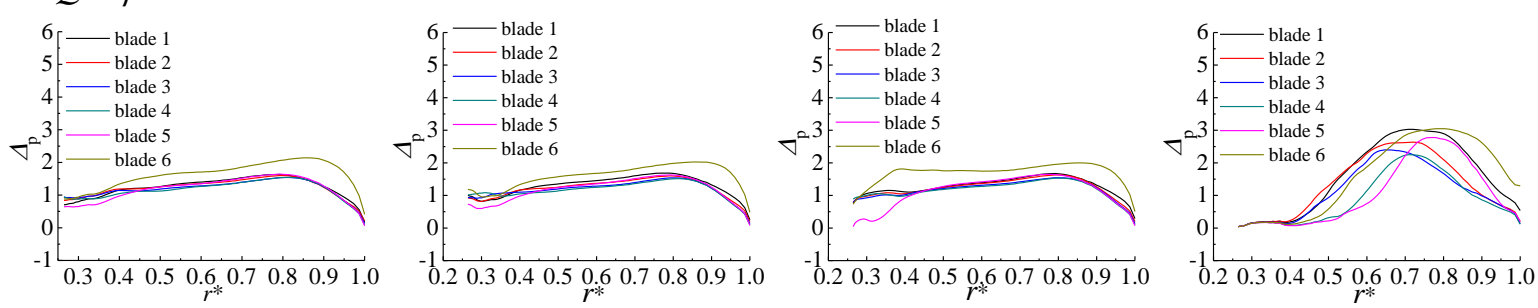

$1.0 Q \Delta \beta=0^{\circ}$

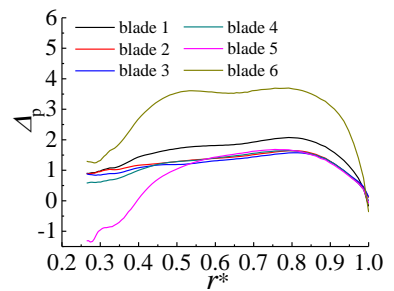

$1.3 Q \Delta \beta=0^{\circ}$

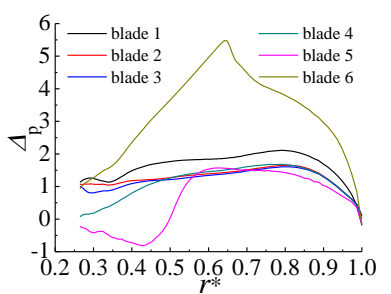

b)

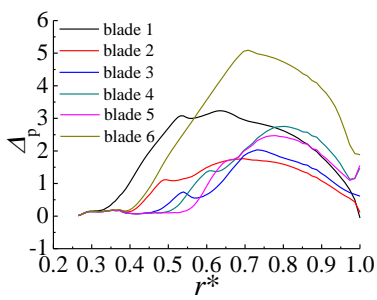

c)

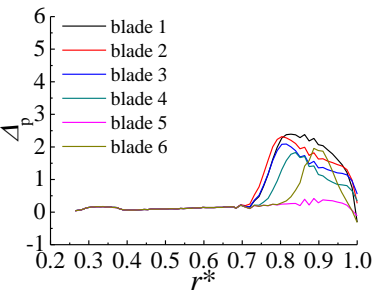

d)

Figure 11: Pressure difference coefficient $\Delta p$ of blades on the cross section of the impeller; a) $\sigma=1.6993$, b) $\sigma=0.8717$, c) $\sigma=0.4579$, d) $\sigma=0.2510$.

\section{CONCLUSIONS}

To investigate the influence of inlet attack angle on the cavitation of low-specific-speed centrifugal pump and divide the cavitation evolution stages of this type of pump, this study designed three impellers with different inlet attack angles. The inner cavitation evolution was studied based on numerical and experiment results to provide reference for the optimum design of the anti-cavitation performance of centrifugal pump. The following conclusions were obtained:

1) The flow uniformity at the impeller inlet was improved by the positive inlet attack angle for the low-specific-speed pump, whereas the inlet attack angle exerted little influence on hydraulic performance in the noncavitation condition as it varied from $-8^{\circ}$ to $8^{\circ}$.

2) The cavitation evolution in the centrifugal pump can be divided into four stages, namely, incipient, critical, developed, and complete cavitation. Among all of the flow structures in the impeller, those at the stage of developed cavitation were the most complicated due to the re-entrant jet in the front zone of the cavity. 
3) Regardless of whether cavitation occurred or not, blade loading was affected by volute type. A drastic increase in blade loading occurred at the trailing edge of the blades under low flow rate, whereas under the design or high flow rates, the distribution of blade loading was uniform before critical cavitation. The non-uniformity gradually increased until the stage of complete cavitation was reached, and about $3 / 5$ of the blade length lost its working capability. Moreover, the pressure difference on the blade close to the tongue was higher than that on the other blades. The incipient location of cavitation appeared on the suction side of the leading edge of the blade close to the tongue.

This study combined numerical simulation with experimentation on external characteristics to investigate the flow field at each stage of cavitation evolution. The influence of inlet attack angle on the cavitation of the low-specific-speed centrifugal pump was also determined. This study can provide guidance for the optimization of the anti-cavitation performance of low-specific-speed centrifugal pump. However, visualization experiment was not conducted. Future studies could investigate cavitation evolution by combining numerical simulation and visualization experiment.

\section{REFERENCES}

[1] Franc, J.-P.; Michel, J.-M. (2006). Fundamentals of Cavitation, Springer Science \& Business Media, New York

[2] Posa, A.; Lippolis, A. (2019). Effect of working conditions and diffuser setting angle on pressure fluctuations within a centrifugal pump, International Journal of Heat and Fluid Flow, Vol. 75, 44-60, doi:10.1016/j.ijheatfluidflow.2018.11.011

[3] Gao, B.; Sun, X.; Yang, M.; Zhang, N. (2014). Characteristics of unsteady excitation induced by cavitating flow in centrifugal pumps, Journal of Mechanical Engineering, Vol. 50, No. 16, 199205, doi:10.3901/jme.2014.16.199

[4] Adamkowski, A.; Henke, A.; Lewandowski, M. (2016). Resonance of torsional vibrations of centrifugal pump shafts due to cavitation erosion of pump impellers, Engineering Failure Analysis, Vol. 70, 56-72, doi:10.1016/j.engfailanal.2016.07.011

[5] Binama, M.; Muhirwa, A.; Bisengimana, E. (2016). Cavitation effects in centrifugal pumps - a review, Journal of Engineering Research and Applications, Vol. 6, No. 5, 52-63

[6] Lu, Z.; He, X.; Wang, C. (2018). Influencing factors of self-priming time of multistage selfpriming centrifugal pump, DYNA - Ingenieria e Industria, Vol. 93, No. 6, 630-635, doi: $10.6036 / 8930$

[7] Ključanin, D.; Manđuka, A. (2019). The cantilever beams analysis by the means of the first-order shear deformation and the Euler-Bernoulli theory, Tehnicki glasnik - Technical Journal, Vol. 13, No. 1, 63-67, doi: 10.31803/tg-20180802210608

[8] Zhou, X.; Zhang, Y. X.; Ji, Z. L.; Chen, L. (2012). Hydraulic design and performance analysis of low specific speed centrifugal pump, IOP Conference Series: Earth and Environmental Science, Vol. 15, No. 3, Paper 032023, 8 pages, doi:10.1088/1755-1315/15/3/032023

[9] Zhu, B.; Chen, H.-X. (2012). Cavitating suppression of low specific speed centrifugal pump the gap drainage blades, Journal of Hydrodynamics, Vol. 24, No. 5, 729-736, doi:10.1016/S10016058(11)60297-7

[10] Luo, X.-W.; Ji, B.; Tsujimoto, Y. (2016). A review of cavitation in hydraulic machinery, Journal of Hydrodynamics, Vol. 28, No. 3, 335-358, doi:10.1016/S1001-6058(16)60638-8

[11] Yan, H.; Li, Q.; Zhang, Y.; Shi, H. X.; Vnenkovskaia, V. (2018). Optimization of cavitating flow characteristics on RBSS of waterjet pumps, International Journal of Simulation Modelling, Vol. 17, No. 2, 271-283, doi:10.2507/IJSIMM17(2)427

[12] Blecich, P.; Senčić, T.; Wolf, I.; Bonefačić, I. (2018). Numerical investigation of heat and mass transfer inside a wet cooling tower, Tehnicki glasnik - Technical Journal, Vol. 12, No. 3, 131138, doi:10.31803/tg-20171017145907

[13] Rakibuzzaman, M.; Kim, K.; Suh, S.-H. (2008). Numerical and experimental investigation of cavitation flows in a multistage centrifugal pump, Journal of Mechanical Science and Technology, Vol. 32, No. 3, 1071-1078, doi:10.1007/s12206-018-0209-6 
[14] Iga, Y.; Hashizume, K.; Yoshida, Y. (2011). Numerical analysis of three types of cavitation surge in cascade, Journal of Fluids Engineering, Vol. 133, No. 7, Paper 071102, 13 pages, doi: $10.1115 / 1.4003663$

[15] Kunz, R. F.; Boger, D. A.; Stinebring, D. R.; Chyczewski, T. S.; Lindau, J. W.; Howard, J. G.; Venkateswaran, S.; Govindan, T. R. (2000). A preconditioned Navier-Stokes method for twophase flows with application to cavitation prediction, Computers \& Fluids, Vol. 29, No. 8, 849875, doi:10.1016/s0045-7930(99)00039-0

[16] Ye, Y.; Zhu, X.; Lai, F.; Li, G. (2017). Application of the semi-analytical cavitation model to flows in a centrifugal pump, International Communications in Heat and Mass Transfer, Vol. 86, 92-100, doi:10.1016/j.icheatmasstransfer.2017.04.021

[17] Luo, X.; Zhang, Y.; Peng, J.; Xu, H. (2008). Effect of impeller inlet geometry on centrifugal pump cavitation performance, Journal of Tsinghua University (Science and Technology), Vol. 48, No. 5, 836-839, doi:10.3321/j.issn:1000-0054.2008.05.019

[18] Luo, X.; Liu, S.; Zhang, Y.; Xu, H. (2008). Cavitation in semi-open centrifugal impellers for a miniature pump, Frontiers of Energy and Power Engineering in China, Vol. 2, No. 1, 31-35, doi: $10.1007 / \mathrm{s} 11708-008-0011-8$

[19] Gao, B.; Sun, X.; Yang, M.; Zhang, N. (2014). Characteristics of unsteady excitation induced by cavitating flow in centrifugal pumps, Journal of Mechanical Engineering, Vol. 50, No. 16, 199205, doi:10.3901/JME.2014.16.199

[20] Medvitz, R. B.; Kunz, R. F.; Boger, D. A.; Lindau, J. W.; Yocum, A. M.; Pauley, L. L. (2002). Performance analysis of cavitating flow in centrifugal pumps using multiphase CFD, Journal of Fluid Engineering, Vol. 124, No. 2, 377-383, doi:10.1115/1.1457453

[21] Tang, X.; Zou, M.; Wang, F.; Li, X.; Shi, X. (2017). Comprehensive numerical investigations of unsteady internal flows and cavitation characteristics in double-suction centrifugal pump, Mathematical Problems in Engineering, Vol. 2017, Paper 5013826, 13 pages, doi:10.1155/2017/5013826

[22] Bakir, F.; Rey, R.; Gerber, A. G.; Belamri, T.; Hutchinson, B. (2004). Numerical and experimental investigations of the cavitating behavior of an inducer, International Journal of Rotating Machinery, Vol. 10, No. 1, Paper 690740, 11 pages, doi:10.1155/S1023621X04000028

[23] Azad, S.; Lotfi, H.; Riasi, A. (2019). The effects of viscoelastic fluid on the cavitation inception and development within a centrifugal pump: an experimental study, International Communications in Heat and Mass Transfer, Vol. 107, 106-113, doi:10.1016/ j.icheatmasstransfer.2019.05.008

[24] Lu, J.; Yuan, S.; Siva, P.; Yuan, J.; Ren, X.; Zhou, B. (2017). The characteristics investigation under the unsteady cavitation condition in a centrifugal pump, Journal of Mechanical Science and Technology, Vol. 31, No. 3, 1213-1222, doi:10.1007/s12206-017-0220-3

[25] Guo, X.; Zhu, L.; Zhu, Z.; Cui, B.; Li, Y. (2015). Numerical and experimental investigations on the cavitation characteristics of a high-speed centrifugal pump with a splitter-blade inducer, Journal of Mechanical Science and Technology, Vol. 29, No. 1, 259-267, doi:10.1007/s12206014-1232-x 